\title{
MENTAL HEALTH AND THE LAW: PARTNERS IN ADVANCING HUMAN RIGHTS
}

\author{
Frank M. OChBERG $\dagger$ \\ BERTRAM S. BROWN $\dagger \dagger$
}

It is a pleasure to contribute to this issue honoring Chief Judge David Bazelon. His broad and humanistic approach has helped to further understanding between law and mental health, and the reforms he has promoted benefit both fields. Both law and mental health are rooted in individuals' struggle to live successfully together, to assist each other, to help with human suffering, and to absorb the immense and complex variety of human behavior. Chief Judge Bazelon has observed that people tend to think of the "law" as a fixed body of principles which the judge "finds"; he stresses that they tend to overlook "the kind of practical enterprise it really is. . . . At every turn it involves complex interactions of persons, institutions, diverse values, and more." 1 The same is true of the field of mental health. It too is a practical enterprise, full of complications, mirroring the changing attitudes of the community, reflecting both new knowledge and the public's willingness to assume responsibilities.

Each century has its major struggles, its historic problems. Our time has been tragically scarred by war, but has also been characterized by a continuous and valiant struggle to improve the lot of the sick, the needy, the disadvantaged, the mentally ill, and the mentally retarded. We have seen the dawn of enlightenment and acceptance, of people admitting psychological

† Director, Division of Mental Health Service Programs; National Institute of Mental Health; Alcohol, Drug Abuse, and Mental Health Administration; Department of Health, Education, and Welfare. A.B. 1961, Harvard University; M.D. 1965, Johns Hopkins University.

†† Director, National Institute of Mental Health. B.A. 1952, Brooklyn College; M.D. 1956, Cornell University; M.P.H. 1960, Harvard University.

The authors gratefully acknowledge the assistance of Clarissa Wittenberg in the preparation of this article.

${ }^{2}$ D. Bazelon, Equal Justice for the Unequal 3-4 (1961). 
problems and asking for help, of a greater commitment to research, and of the development of new medications, new therapies, new insights, and new methods. We have seen the development of new facilities and the restructuring of those facilities to keep pace with the times. We have observed in our own lifetime that, whereas mental illness was once the deepest shame, it is now regarded and treated without such severe stigma. From the use of "cuffs" and "strait jackets," we have moved to new and more humane therapies. Our entire social fabric has been affected by the work of Freud. His observations have changed not only our hospitals, but also our schools and even our family life. We have seen the development of the community mental health center movement, the "third revolution" in psychiatry. The first revolution was the institutional reforms of the mid-eighteenth century, the second was the new insights of the psychoanalysts led by Freud. This third revolution, the community mental health center movement, has at its heart the very concerns to which Chief Judge Bazelon refers when he speaks of the importance of the "large perspective of the whole man in a living society." 2

\section{The Community Mental Health Center Movement}

The community mental health center movement focuses on the individual, but with great benefits for the society in which he lives. We are as lacking in neutrality concerning its benefits as Chief Judge Bazelon is concerning reforms in the law.

As a society, we have become increasingly concerned with human rights. Issues which relate to that elusive concept of "the quality of life" are important to us. We have come to ask an unprecedented number of services from our government, at the same time insisting on the rigorous protection of individual rights. We concern ourselves more and more with social and psychiatric issues, pondering, for example, whether a child's emotional needs are met rather than merely asking whether parents house and feed their children adequately.

The community mental health center movement has been concerned with all of these issues. The dignity of the individual

${ }^{2} I d .1$. 
patient is the core concern. Once a man had to be relatively wealthy to have a full range of services available to him; now, in many communites, they are available to all. We know now that recovery from severe mental illness requires full and timely treatment, rehabilitation, and reintegration into a community ready and willing both to accept and to help. Efforts are increasingly being made to treat without hospitalization. Doctors are sensitive to the charge of having become jailers. While commitment was once considered part of positive, responsible, and protective care of a patient, it is now increasingly debated in the courts as well as in medical conferences.

The Community Mental Health Centers Act of $1963{ }^{3}$ based on a study by the Joint Commission on Mental Illness and Health ${ }^{4}$ (a commission chartered by Congress at the request of the American Psychiatric Association ${ }^{5}$ ), provides supporting services for this program of assisting people to find help voluntarily. Unless such services are available, the concept of seeking help on one's own initiative is hollow. President Kennedy aroused great hopes on February 5, 1963, when he presented his message on mental illness and mental retardation. ${ }^{6}$ He proposed the development of community mental health centers across the nation, to coordinate all existing services and to add new services where necessary. The emphasis was on community treatment and continuity of care, on human needs, not on buildings or bureaucracies. In President Kennedy's words,

These centers will focus community resources and provide better community facilities for all aspects of mental health care. Prevention as well as treatment will be a major activity. Located in the patient's own environment and community, the center would make possible a better understanding of his needs, a more cordial atmosphere for his recovery, and a continuum of treatment. As his needs change, the patient could move without delay or difficulty to different services,

342 U.S.C. $\$ \$ 2681-87$ (1970).

4 Joint Commission on Mental Illness and Health, Action for Mental Health (1961).

5 The Joint Commission was set up by Congress pursuant to the Mental Health Study Act of 1955, 42 U.S.C. $\$ 242 b$ (1970).

' Message of President Kennedy to the House of Representatives, 109 Conc. REC. 1837 (1963) (H.R. Doc. No. 58). 
from diagnosis, to cure, to rehabilitation, without need to transfer to different institutions located in different communities. $^{7}$

This human emphasis has been successful, and hopefully will continue to be so, in promoting the continued survival of the centers at a time when all health services are fighting for financial support.

\section{A. The Historical View}

Most major reforms are exceedingly simple in concept, but exceedingly complex in execution. Mental health reform has been no exception to the rule. Furthermore, the struggle has been complicated by many other issues, not the least of which has been the historical background of our nation and its traditional patterns of care of the mentally ill. The plan to move care back to the community caught the imagination of those supporting humane treatment, but worried entrenched interests and tugged at the fears of citizens and the anxieties of old line professionals. ${ }^{8}$ For many patients who had been housed for years in institutions, the possibility of discharge posed great risks and serious problems. When the community mental health centers were first proposed, no one knew that legal challenges concerning the rights of mental patients would soon sweep the country.

In building the community mental health center movement, we deal daily with the residual problems of previous eras, old laws, and old patterns. Historically, this country borrowed many of its attitudes from Europe, where the care of the "dangerously insane" was carried out primarily in asylums and monasteries. There were few distinctions as to whether a man was a criminal or mentally ill; both were under the jurisdiction of the police. ${ }^{9}$ Indeed, in the early years of this country, commitment of the violent or dangerously ill was handled under the authority of the sovereign's police powers. In some ways we have taken two hundred years to change this pattern, in some ways perhaps we never will. ${ }^{10}$

'Id. 1839.

${ }^{8}$ Caplan \& Caplan, Development of Community Psychiaty Concepts, in CoMPreneNSive TeXtbook of Psychiatry 1499 (1967).

"American Bar Foundation, The Mentally Disabled and the law 4-j (1971).

"Id. 1-7. 
When new immigrants settled this land, they had no institutions and few communal operations at all. Life had many harsh realities. The care of the mentally ill began as an expedient way to preserve community and family life and to prevent those who were incompetent from draining a family so that productive work would cease, thereby threatening the whole community. The focus was entirely upon managing the problem and preventing crisis, not on curing the patient. This situation was complicated by then prevalent theories, which often posited a diabolical basis for the disturbance. ${ }^{11}$ Then, as groups of transients or "drifters" developed, roaming from town to town, barely able to function, a solution had to be found. In a strongly Puritan atmosphere that linked work and industry with moral worth and laziness with sin, these people were in danger of ridicule and abuse. Communities began trying to help. In 1676 a court in Pennsylvania gave a poor man whose son was "quyt madd" money to build a little "block-house at Amesland for to put in said madman." 12 Similar incidents occurred in other places. ${ }^{13}$ There were many urgent needs and little community money. Fire companies, schools, and even police and jails were privately owned. Jails were the first priority, and it is understandable that when the mentally ill looked violent or manifested unusual behavior they were confined there.

Doubtless too, despite the fact that asylums had been built early in Europe's history, many immigrants to this country carried with them memories of what dungeons those asylums actually were. Consider this description of Salpetriere in France in 1787:

Patients massed in fours or more in narrow cells; a dirty sack of straw, with vermin crawling through; rats running in troops by night, eating the clothes, the bread, and in time, the flesh of the patients ... poisoned in their insanity worse than before . . . the more delicate perished in little heaps. ${ }^{14}$

In the infamous Bethlehem hospital in London, established in 1247 and commonly called "Bedlam," the outcasts of society

"See generally W. Bromberg, The Mind of MAN 52-55 (1959).

12 American Bar Foundation, supra note 9, at 4.

${ }^{13} \mathrm{Id}$.

14 W. Bromberg, supra note 11 , at 76-77 (quoting Robin, Nouvelles de médicin et de chirurgerie, A Description of Salpetrière, 1787). 
were housed: not only the insane, but also criminals, prostitutes, and the feeble-minded. Unlike other hospitals operated in monasteries, Bedlam became a circus operated for the profit of the warders. Londoners came on Sunday, paid a shilling, and laughed at the inmates. ${ }^{15}$ This tinge of the dark side of life so often associated with the mentally ill is still partially responsible for a powerful pattern of isolating them from the general public.

Early in our history there was little differentiation among individuals considered to be community problems. In 1841 Dorothea Dix brought attention to the mentally ill housed in jails. ${ }^{16}$ She pointed out such abuses as patients chained at night, and in one place found there were no stoves for warmth despite bitter cold. Angered, she sent what are now historic documents ${ }^{17}$ to the Massachusetts legislature, and visited every jail and almshouse in Massachusetts, New Jersey, and many other states. Due to her influence, doctors were added to institutional staffs and thirty-two hospitals were founded or enlarged, including St. Elizabeths in Washington, D.C. ${ }^{18}$ But the reforms of one era are the abuses of another. The mental hospitals, for all their medical staffs, were soon seen as "snakepits," human warehouses. ${ }^{19}$ The effects of institutionalization itself, the molding of already weakened persons into patterns of behavior appropriate to hospitals, limited the capacity of patients to readjust to the community. Experts noted that patients seemingly free of psychiatric illness were unable to leave hospitals and move towards independent patterns of living. ${ }^{20}$ This problem was invisible until the expectation spread that most patients should recover and return to the community. ${ }^{21}$ That it must now be faced is evidence of the progress we have made.

As difficult problems proved resistant to change, "back wards" developed. The pattern of housing the most chronic

${ }^{15} \mathrm{Id} .77$.

${ }^{16}$ Id. 101-03.

${ }_{17}$ Dix, Memorial to the Legislature of Massachusetts on Behalf of the Insane (1843), quoted in id. 102.

${ }^{18} \mathrm{~W}$. BROMBERG, supra note 11 , at 102.

${ }^{19}$ Cumming \& Cumming, Social Equilibrium and Social Change in the Large Mental Hospital, in The Patient and the Mental Hospital (M. Greenblatt ed. 1957).

20 Ochberg, Zarcone \& Hamburg, Symposium on Institutionalization, 13 COMPREHENSIVE PSYCH. 91 (1972).

${ }^{21}$ Cumming \& Cumming, supra note 19. 
patients farthest back in institutions developed. Here they were, in John Kennedy's words, "out of sight and forgotten."22 Work programs, begun to combat the pattern of endless days spent in isolation on wards, began to be seen as exploitative. Indeed, many institutions could hardly operate without this "institutional peonage." Critics described the large hospitals in harsh terms: "On the whole, these public institutions are unmanageably large; they are economically depressed, running on a fraction of the cost of general hospitals, schools or jails; they are chronically understaffed, and they are usually cut off from the mainstream of professional life."23

The door slammed shut for many patients, because the prognosis was extremely guarded for any individual whose difficulties did not abate in the first six months of hospital treatment. ${ }^{24}$ In addition to the risks posed by institutionalization, patients lost their social status. People were classified as "mental patients," a social category rather than a medical condition. ${ }^{25}$ Mental illness has not only social causes, but social consequences as well. Once people are so labeled, the label tends to remain with them, scarcely diluted by the word "former." After a certain point, the damage done by the label of "mental patient" becomes pervasive and permanent, no matter how slight or temporary the actual disturbance was. It is very difficult to prove that someone has become "normal." Since we are all influenced by other's perceptions of us, this becomes an added handicap. Long hospitalizations break family ties. Early intense efforts to visit abate. State hospitals are typically located far from cities, increasing the difficult of maintaining contact. Also, in the past, although this is slowly changing, phone calls and even letters could not be freely exchanged, further causing distance between family and friends.

There is a risk that after hospitalization a patient will not return to work, or will be forced to work at a lower occupational level. We know now that, although some adjustments may be necessary, most people with psychiatric problems can continue

${ }^{22}$ Message of President Kennedy, supra note 6, at 1838.

${ }^{23}$ Cumming \& Cumming, supra note 19, at 50.

${ }^{24}$ Lehmann, Schizophrenia IV: Clinical Features, in Comprenensive TeXtвook of Psychiatry, supra note 8, at 646 .

${ }^{25}$ Cumming, Care for the Mentally Ill, American Style, in Organizing for Community WeLfare 122 (M. Zald ed. 1967). 
to work. Partial hospitalization programs and day and night hospitals help to protect both family bonds and working patterns. One study of a labor union mental health clinic that focused on the relationship between the patient's ability to work and his psychological problems found that the ability to work and the degree of pathology are not directly related ${ }^{26}$ Given two individuals with similar problems, one might be able to return successfully to work and the other might not. ${ }^{27}$ Night psychiatric clinics, where assistance could be sought without a loss of working time, were found to be very valuable in helping people through difficult times. Results showed too that the more problems that surround the person, the more difficulty he has in returning to work. A man with family problems, an unsympathetic employer, no available psychiatric help, no money, and no place to stay is in more serious trouble than a person who has a psychiatric problem in a more supportive set of circumstances. ${ }^{28} \mathrm{~A}$ community mental health center has to be designed to be helpful to both of these individuals, for it is set up to provide such disparate services as consultation to an employer and the prescription of the right medication, which are seen as equally valuable.

\section{B. The Community Mental Health Care Center-Some Examples}

The dream was to have centers serving 1,500 catchment areas throughout the country. To date, there are 550 community mental health centers, serving over a third of our citizens. ${ }^{29}$ Each center offers all intensities of service: hospital inpatient, clinic outpatient, day treatment or some form of partial hospitalization, preventive and early case finding programs, and crisis care. Delivery of services is coordinated, and (ideally) all services are located within the community's geographical boundaries. Each person has access to this range of services regardless of his or her ability to pay. Each community was charged with finding ways to integrate existing services, and then to fill in the gaps. In most communities, boards of citizen advisors were developed to assist in this new organizational ef-

${ }^{26}$ Wittenberg, A Labor Union Mental Health Program, 3 Mental Health Program Rep. 211 (1969).

${ }^{27}$ Id. 221.

${ }^{28}$ Id. 222.

${ }^{29}$ The statistic is based on figures gathered by the authors. 
fort. Each center reflects its community. Some are intensely concerned with minority issues, others are not. Some are rural, tied together by professionals who travel, some are in urban settings sharing quarters with shops and stores, still others are in small towns.

An impressive example of an urban center is the Westside Community Mental Health Center in San Francisco. ${ }^{\mathbf{3 0}}$ Here minority groups have actively participated and have had an important influence. Located in an area that is home to Blacks, Japanese, Russians, Filipinos, Jews, Chinese, and native Americans, as well as the "flower children" of the late 1960's, it has had to meet diverse needs and to change over time. In addition to becoming culturally sophisticated, this center has served as a training ground for many young minority members. The approach of the center has not been that there are endless unmeetable needs in their area, but that there are only a finite number of people with definable needs, which can be met. It has maintained a continuous survey to define these needs, and has been remarkably successful. ${ }^{31}$ Last year only five people needed to be treated for psychiatric problems outside of the community, and those individuals were helped in the special community mental health center ward operated in the state hospital nearby. ${ }^{32}$

In a far different setting, in northeastern Vermont near the Canadian border, is a community mental health center called the Northeast Kingdom Mental Health Service. It provides services for 50,000 people who live in an area of over 2,500 square miles. ${ }^{33}$ Many of them are of French-Canadian descent. By and large the area is made up of small towns and villages, few of which previously had any mental health agencies at all. The temperature falls to forty degrees below zero in the winter, and snow blocks transportation. The Northeast Kingdom Mental Health Service has been decentralized: one office is in Newport, a town of fifty thousand; one is in St.

${ }^{30}$ Gattozzi, San Francisco Westside: A Community Mental Health Center Serves the People, 5 Mental. Health Program Rep. 174 (1972).

${ }^{31}$ Id. 186-87.

${ }^{32}$ Personal communication from Dr. William Goldman, past director of W'estside Community Mental Health Center, Apr. 30, 1974.

${ }^{33}$ Yahraes, Northeast Kingdom Center Offers Treasury of Services, in 6 Mental Health Program Rep. 201 (1973). 
Johnsbury, a town of eight thousand; and a third office, in an interesting "between-the-states" arrangement, is in Colebrook, just over the Vermont-New Hampshire line. This New Hampshire town is the main shopping center for many nearby Vermont residents. Outreach centers were tried and then discontinued, as they presented an insurmountable travel problem for the staff. Even so, the majority of people in this sparsely settled area are within twenty miles of an office, and very few are more than fifty miles from one. In addition to the basic programs, this center has added a foster home for unmanageable adolescents and troubled children, which serves as an emergency center and diagnostic facility as well. It also has a school consultation program, a speech therapist, a summer activity program for problem children, sheltered workshops, services to staff in nearby correctional institutions, an open house for young people (part of a drug treatment program), and services to promote physical as well as mental health. In addition, the center has coordinated work with the Public Health Nursing Program in the area, which includes nursing services, physical therapy, and mental health counseling. A well child clinic has been developed. All of this will eventually lead to a program of promoting and protecting both physical and mental health for all family members. ${ }^{34}$

Mountain Mental Health Services serves the Appalachian area of eastern Kentucky, a five-county area with 160,000 persons, many of whom live in isolated hollows in the hills. It is one of the poorest areas of our land, with more than half the families having incomes under $\$ 3,000 .{ }^{35}$ Here, the professionals travel. They have worked with the United Mine Workers in an effort to improve services in the area. This program grew out of an innovative social worker-nurse clinical team that had developed ways of working with the people in this area of the Cumberland Mountains. Prior to the program, there was not a psychiatrist, a clinical psychologist, or a psychiatric nurse in any of the five counties covered. The nearest mental hospital was Eastern State in Lexington, five hours away over rugged mountain roads. A prime concern was to reduce both mental

\footnotetext{
${ }^{34} I d$.

${ }^{35}$ Yahraes, $A$ Community Mental Health Center in Appalachia, 5 Mental Health ProGRAM REP. 90, 9] (1971).
} 
hospital admissions, which have been high, and the number of patients readmitted a number of times. Evaluation surveys are being conducted, with indications that the programs have been successful. ${ }^{36}$

In summary, the community mental health center program has not only moved patients from state hospitals to community centers, but has also prevented hospitalization entirely in some cases. Programs have been fostered where few existed in the past. In 1963 , there were $504,604^{37}$ patients in state hospitals; in 1973, the figure stood at $248,562 .^{38}$ The basic objective is being met: the number of patients in state hospitals has been cut in half, and many more services are being provided in the home community.

\section{Developing Ideas about Care}

Progress is being made, but there are still problems. Not only have many people been helped, and hospitalization avoided, but many long-term chronic patients have also been placed in sheltered housing in the community. This process has grown with a new momentum over the last twenty years. Many of these patients are vulnerable and quite incapacitated. They are also more visible than they were in the custodial back wards. One critical newspaper article called this a movement "from back wards to back alleys." 39 The accusation was that our society tends to believe that "expressing outrage or organizing a campaign or passing a new law" solves a problem. ${ }^{40}$ The authors' complaint was that "despite good intentions, we have actually gone from the 19th Century snake pits back toward the Middle Ages, when the mentally ill roamed the streets, sick, helpless and isolated." ${ }^{41}$ This is effective imagery, but it is neither accurate nor acute criticism, nor is it factually correct. After a century of scientific and social improvements affecting the mentally ill in America, and after a decade of intense fed-

${ }^{36} I d$.

37 Division of Biometry, National Institute of Mental Health, Provisional Patient Movement and Administrative Data-State and County Mental Hospital InPatient Services July 1, 1972-June 30, 1973, Statistical Note 106 (1974).

${ }^{38} I d$.

39 Trotter \& Kuttner, The Mentally Ill: From Back Wards to Back Alleys, Washington Post, Feb. 24, 1974, § C, at 1, col. 5.

${ }^{40} I d$.

${ }^{41} I d$. 
eral effort, there is more care available, there are higher standards expected and enforced, and there are better trained, greater numbers of professionals who care. In addition, there is an aroused and educated citizenry which continually presses for further improvement.

This is not to say there are no problems, or that all patients are ideally treated. We have many serious problems. Many patients who are now in foster care have been hospitalized for the majority of their adult years and need continuous support and rehabilitation. Halfway houses and sheltered living arrangements are needed, but are difficult to establish. Many communities have unrealistic fears about having a halfway house or a foster home in their midst. ${ }^{42}$ Professionals are concerned about the recent Supreme Court decision in Village of Belle Terre v. Boraas, ${ }^{43}$ which upheld a village ordinance restricting the use of land to one-family dwellings. Although the case involved specifically a group of college students, the holding may create barriers to the establishment of sheltered housing. The decision may protect "charm," but it may also inhibit social change. We need an increase in public debate and public awareness of our successes, of the problems in a community that impede an individual from receiving the help necessary to become as self-sufficient as possible.

\section{InvoluntaRy COMMITMENT}

\section{A. Current State Approaches}

A major trend, consistent with our concern for individual rights and our regard for the individual's control over his own life, is that of voluntary commitments. For a number of years, professionals have been aware that the person who engages in treatment voluntarily often benefits more than someone who is involuntarily committed. Although we have historically committed people to mental hospitals rather easily, this pattern is now reversing. Even a patient needing long-term hospitalization can often receive it on a voluntary basis. In this way civil rights are protected and less psychological damage is done. It

${ }^{42}$ F. Ochberg, Community Cure for the Mentally Disabled, March 19, 1974 (unpublished paper on file with the author).

43416 U.S. I (1974). 
eases the rehabilitative process at the point when the person has to be encouraged again to resume initiative and assume responsibilities. Each year more states encourage voluntary commitment and more stringently limit grounds for involuntary commitment. ${ }^{44}$ Danger to self or others is increasingly accepted as the only legitimate standard for involantary commitment. Nine states-Arizona, California, Florida, Massachusetts, Montana, Nevada, New Hampshire, North Carolina, and Washington-and the District of Columbia currently restrict involuntary commitment to dangerous patients. ${ }^{45}$ Most states still use a vague standard of "dangerousness" and "in need of treatment."46

Some new state codes also limit the time of commitment. The California law, the Lanterman-Petris-Short Act, ${ }^{47}$ allows, in addition to the three days for evaluation ${ }^{48}$ and fourteen days for intensive treatment, ${ }^{49}$ only fourteen days of commitment for persons assumed to be suicidal ${ }^{50}$ and ninety days for those presumed to be homicidal or assaultive. ${ }^{51}$ Within thirteen days of admission, ninety-five percent of all supposedly suicidal patients and ninety-eight percent of all supposedly dangerous-toothers patients are discharged..$^{52}$ They may, of course, re-enter the hospital on a voluntary basis. In 1969-71, a California study showed that, in general, lengths of hospitalizations were substantially reduced and that although the number of admissions to California's mental institutions increased, continuing a fiveyear trend, the overall census had declined dramatically. ${ }^{53}$

${ }^{44}$ A. McGarry, Dangerousness and Civil Commitment in Massachusetts, 1974 (unpublished paper on file at the Law-Medicine Institute, Harvard University).

45 Ariz. Rev. Stat. Ann. § 36-514 (Supp. 1973); Cal. Welf. \& Inst'ns Code §§ §260, 5300 (West 1972); D.C. Code AnN. § 21-545 (1973); Fla. Stat. ANn. $§ 394.463$ (Supp. 1974); Mass. Gen. Laws ANN. ch. 123, §§ 1, 8 (Supp. 1974); Mont. Rev. Codes Ann. § 38-208 (Supp. 1974); Nev. Rev. Stat. \$ 433.695 (1973); N.H. Rev. Stat. AnN. § 135-B:26 (Supp. 1973); N.C. Gen. Stat. § 122-58.8 (Supp. 1974); Wash. Rev. Code $\$ 71.05-280$ (Supp. 1973). The statutes and their application are summarized in AMERICAN BAR Foundation, supra note 9, at 72-76. For a detailed compilation of the laws of all 50 states, see Developments in the Law: Civil Commitment of the Mentally Ill, 87 Hakv. L. REv. 1190, 1202-07 (1974).

${ }^{46}$ American Bar Foundation, supra note 9, at 72-76.

${ }^{47}$ CAL. W'elf. \& INST'NS Code $\$ \S 5000-401$ (West 1972).

${ }^{48}$ Id. $\$ 5206$.

4. $I d$. $\$ 5250$.

so Id. $\$ 5260$.

sI Id. $\$ 5300$.

32 See A. Urmer, A Study of California's New Mental Health Law (1969-1971), at $1-\overline{\mathbf{j}}$ (1974).

${ }^{53} I d$. 
In Massachusetts, the dangerousness standard is the sole basis for involuntary commitment. ${ }^{54}$ Commitment can be ordered only if the failure to hospitalize an individual would create a likelihood of serious harm by reason of mental illness. "Likelihood of serious harm" is defined as:

(1) a substantial risk of physical harm to the person himself as manifested by evidence of threats of, or attempts at, suicide or serious bodily harm;

(2) a substantial risk of physical harm to other persons as manifested by evidence of homicidal or other violent behavior or evidence that others are placed in reasonable fear of violent behavior and serious physical harm to them; or

(3) a very substantial risk of physical impairment or injury to the person himself as manifested by evidence that such person's judgment is so affected that he is unable to protect himself in the community and that reasonable provision for his protection is not available in the community. ${ }^{55}$

Evidence of dangerous behavior must be presented at a hearing. The new code also abolished indefinite commitments. The first order of commitment lasts only six months, and subsequent orders can only extend for one year's time. ${ }^{56}$

In the fiscal year before the new code was enacted, 9,936 patients, or $72.6 \%$ of the total hospital admissions to Massachusetts state civil hospitals, were involuntary. ${ }^{57}$ In the first year after the code, only 2,924 , or $23.2 \%$, were involuntary. ${ }^{58} \mathrm{~Pa}$ tients under the new voluntary admissions can leave the hospital after giving three days notice. The hospital authorities can petition for commitment, but this option has rarely been exercised.59 According to Dr. A. Louis McGarry, head of the Department of Legal Medicine, there have been no crises from

${ }^{54}$ Mass. Gen. Laws Ann. ch. 123, §§ 1, 8 (Supp. 1974). See Joorst \& McGarry, Massachusetts Mental Health Code: Promise and Performance, 60 A.B.A.J. 95 (1974).

${ }^{55}$ Mass. Gen. Laws AnN. ch. 123, § 1 (1972).

${ }^{56}$ Joorst \& McGarry, supra note 54, at 97.

${ }^{57}$ Id. 95.

${ }^{58}$ Id.

${ }^{59} \mathrm{Id}$. 
either the professional or institutional point of view, and none from the community viewpoint either. ${ }^{60}$

\section{B. The Problem of Dangerousness}

The mental patient's potential dangerousness is another serious issue which concerns both professionals and laymen. We see and remember headlines such as, "Former Mental Patient Kills Wife." We do not remember that thousands of former mental patients go about their business without harming or frightening anyone. We have allowed preventive detention for mental patients to a degree that would not be tolerated for any other group in our society. Psychiatrists generally have been deeply concerned about their responsibility for protecting the community and have tended to err on the side of caution. Research to date has shown that most mental patients are no more dangerous than the general population. ${ }^{61}$ Some, whose illnesses cause withdrawal and disorganization, are far less dangerous than the community in which they live. We know not only that most individuals released from hospitals for the criminally insane have a lower recidivism rate than parolees from felony prisons, but that very few of them pose considerable danger. ${ }^{62}$

Evaluation of patients released from two maximum security hospitals, Mattawan and Dannemore, as a result of the Baxstrom decision, ${ }^{63}$ in which the United States Supreme Court held that almost a thousand "dangerous" patients were improperly confined, shows there was little subsequent criminal activity when these patients were moved to open mental hospitals. ${ }^{64}$ In Massachusetts, a similar overestimation was found concerning the potential dangerousness of patients confined at Bridgewater State Hospital when the Baxstrom decision was

${ }^{60}$ Personal communication from Dr. Louis McGarry, Director of Legal Medicine, Commonwealth of Massachusetts, Apr. 30, 1974.

${ }^{61}$ Rappeport, The Problem of the Dangerousness of the Mentally Ill, in THE CLINICAL Evaluation of Dangerousness of the Mentally Ili 4 (J. Rappeport ed. 1967).

${ }^{62}$ See McGarry \& Bendt, Criminal vs. Civil Commitment of Psychotic Offenders: $A$ Seven-Year Follow-Up, 125 AM. J. PsYch. 1387 (1969).

${ }^{63}$ Baxstrom v. Herold, 383 U.S. 107 (1966).

${ }^{64} \mathrm{H}$. Steadman, Dangerousness, Due Process, and the Criminally Insane, July $1,1.973$. 
applied there. ${ }^{65}$ Steadman has pointed out that "dangerousness" tends to be decided on the basis of previously committed acts, and that therefore in many cases the contribution of the psychiatrist in this labeling process has no strictly psychiatric component. ${ }^{66}$

While the prediction of danger remains difficult, we know that some signs are significant. Evidence of threats of either homicide or suicide must be taken seriously. Family problems combined with mental illness may be ominous. It has been found that when mental patients are assaultive, they tend to be so with a family member or a close associate. ${ }^{67}$ The addition of a pattern of alcoholism to any other problem adds to the risk of an assaultive act. ${ }^{68}$ Past aggressive acts may be suggestive of future ones. ${ }^{69}$ Evidence of antisocial childhood activity is somewhat correlated with adult assaultiveness. ${ }^{70}$ The presence of some types of brain disease is also associated with an increased potential for dangerous acts. ${ }^{71}$ It must again be stated, however, that the mental patient poses no more threat and frequently is less dangerous than the general population. ${ }^{\mathbf{7 2}}$

For the time being, then, we have some individuals who need high security settings for at least short periods. Increasingly our large hospitals are "unlocked." Although there is considerable supervision, patients are not restrained as they once were. One study group in Massachusetts has recommended high security treatment centers for both civilly committed noncriminal and mentally ill criminal offenders. A minimum of one such center per region, serving between ten and twenty patients, is envisioned. It is also suggested that each of these centers should operate a halfway house, thus further extending the supervision possible for such patients. The group emphasizes that these centers should not be mini-prisons, but rather intensive treatment facilities. ${ }^{73}$

\footnotetext{
${ }^{65}$ A. McGarry, supra note 44.

${ }^{66} \mathrm{H}$. Steadman, The Determination of Dangerousness in New York, May 6, 1974 (paper presented at the 1974 Annual Meeting of the American Psychiatric Association).

${ }^{67}$ Gulevich \& Bourne, Mental Illness and Violence, in Violence ANd the Struggle FOR EXISTENCE 317 (1970).

${ }^{68}$ Id. 319-20.

${ }^{69}$ Id. 321.

${ }^{70} \mathrm{Id}$.

71 Id. 317.

${ }^{72}$ See id. 309-26.

${ }^{73}$ Subcommitte on Mental Hospitals and Correction, United Community
} 
In the domain of "commitment" and the "evaluation of dangerousness," the legal and mental health fields have traditionally intersected. The decision to commit on the basis of "potential" danger, when no act has been committed, poses serious moral and legal questions. Research must continue and findings must be widely disseminated, so that all persons involved in such evaluations can keep current with available information.

The community mental health center movement, with its close ties to specific communities, is developing ways of meeting many mental health problems. Services designed to keep or return people to the community have made mental patients more visible. But they have also protected the rights of patients to privacy and normal living, as far as is possible, since services are given without attaching stigma. Even so, difficult problems, such as how to change deep-seated community attitudes about the mentally ill, still exist. The field of mental health has gradually increased its role in the determination of legal issues, and lawyers need to take a more active, informed role in mental health issues. With regard to commitment in particular, there is need for communication between the courts and the clinicians. The complexity of the problems demands both a high level of sophistication and highly individualized decisions.

\section{Conclusion}

The lot of the mentally ill individual is improving in this country. The problems with which we struggle now are to a large extent the problems of our successes. We have so minimized the restraints in our hospitals that we have a new dilemma. Having moved people from back wards to the community, we have new problems. We need increasing support for community-based facilities and an enlightened public. We are increasingly concerned with the rights of the mentally ill. Slowly, but surely, our practice of mental health reflects new attitudes. We have a responsibility to learn as much as possible about violence and assaultive behavior, so that those who need confinement can be confined and those who pose little or no

Services, Department of Mental. Health, Hospital Planning Project of Boston. Massachusetts, Report of the Task Force on the Adult Psychiatric Offender (1973). 
threat can be treated in another manner. There should be considerable cross-education and discussion between the members of the fields of law and mental health. Judge Bazelon's unusual understanding of the field of mental health has made him an informed and valuable critic, and he himself has a special role with regard to bringing contemporary insights into the court when dealing with psychiatric issues.

We cannot and should not ignore the problem. For the foreseeable future, the mentally ill, like the poor, will be with us. We cannot shrug them off, ignore them, or unduly fear them without damaging ourselves and our society. More and more groups are forming to promote patient rights. Some are articulate and should be heard. One patient wrote:

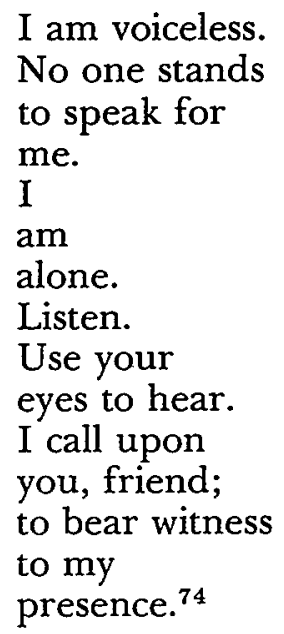

The process of law and the field of mental health are inextricably intertwined in this endeavor to "listen to the voiceless" and to continue to try to improve the human condition.

${ }^{74} \mathrm{E}$. Link, in Voices from the Asylum 144 (M. Glenn ed. 1974). 